PAPER

\title{
Association of a polymorphism of the transforming growth factor- $\beta 1$ gene with cerebral amyloid angiopathy
}

\section{T Hamaguchi, S Okino, N Sodeyama, Y Itoh, A Takahashi, E Otomo, M Matsushita, H Mizusawa, M Yamada}

See end of article for authors' affiliations

Correspondence to: Professor Masahito Yamada, Department of Neurology and Neurobiology of Aging, Kanazawa University Graduate School of Medical Science, 13-1, Takara-machi, Kanazawa 920-8640, Japan; m-yamada@med. kanazawa-u.ac.jp

Received

12 December 2003

Revised version received 12 August 2004

Accepted 27 August 2004
J Neurol Neurosurg Psychiatry 2005;76:696-699. doi: 10.1136/jnnp.2003.034454

Background: A recent study showed that transforming growth factor- $\beta 1$ (TGF- $\beta 1$ ) induces amyloid- $\beta$ deposition in cerebral blood vessels and meninges of a transgenic mouse model of Alzheimer's disease (AD), and that TGF- $\beta 1$ mRNA levels are correlated with cerebral amyloid angiopathy (CAA) in human AD brains. A T/C polymorphism at codon 10 in exon 1 of the TGF- $\beta 1$ gene has been reported to be associated with the serum TGF- $\beta 1$ concentration. We investigated whether the TGF- $\beta 1$ polymorphism is associated with the risk of CAA.

Methods: The association between the severity of CAA and the T/C polymorphism at codon 10 in exon 1 of the TGF- $\beta 1$ was investigated in 167 elderly Japanese autopsy cases, including 73 patients with AD. The apolipoprotein $\mathrm{E}(\mathrm{APOE})$ genotype was also determined.

Results: The genotypes (TT/ TC/ CC) were associated with the severity of CAA significantly in all patients $(p=0.0026)$, in non-AD patients $(p=0.011)$, and APOE non- $\epsilon 4$ carriers ( $p=0.0099)$, but not in $A D$ patients or $A P O E \in 4$ carriers. The number of the T alleles positively correlated with the severity of CAA in all patients $(p=0.0011)$, non-AD patients $(p=0.0026)$, and $A P O E$ non- $\epsilon 4$ carriers $(p=0.0028)$, but not in $A D$ patients or $A P O E \in 4$ carriers. The polymorphism was not significantly associated with $A D$.

Conclusions: Our results suggest that the polymorphism in TGF- $\beta 1$ is associated with the severity of CAA, especially in non-AD patients and $A P O E$ non- $\epsilon 4$ carriers.
C erebral amyloid angiopathy (CAA) is a cerebrovascular amyloid deposition related to intracerebral haemorrhage and other cerebrovascular disorders. ${ }^{12}$ CAA is commonly found in the elderly as well as in Alzheimer's disease $(\mathrm{AD}),{ }^{12}$ and some genetic risk factors for $\mathrm{AD}$ have been reported to be associated with sporadic CAA. ${ }^{3-10}$ The $\epsilon 4$ allele of the apolipoprotein $\mathrm{E}$ (apoE) gene (APOE), an established risk factor of $\mathrm{AD}$, has been suggested to be a risk factor of $\mathrm{CAA}^{3}{ }^{4}$ although this was not evident in some populations ${ }^{56}$ and the $A P O E \in 2$ allele may be associated with CAA-related haemorrhage. ${ }^{7}$ We previously reported that the polymorphisms in the presenilin- $1, \alpha_{1}$-antichymotrypsin, and neprilysin genes may be associated with sporadic CAA. ${ }^{8-10} \mathrm{AD}$ and CAA share risk factors in the common pathogenetic process of amyloid $\beta$ protein $(A \beta)$ deposition.

The multifunctional cytokine transforming growth factor$\beta 1$ (TGF- $\beta 1$ ) is a potent regulator of injury and inflammatory responses in the central nervous system ${ }^{11}$ and has been implicated in cerebral amyloid deposition ${ }^{12-14}$ and $\mathrm{AD}$ pathogenesis. ${ }^{11}{ }^{15}{ }^{16}$ Cerebral TGF- $\beta 1$ mRNA levels are correlated positively with the extent of amyloid deposition in cerebral blood vessels in $\mathrm{AD}$ cases. ${ }^{12}$ Astroglial overproduction of TGF- $\beta 1$ in aged transgenic mice expressing the human $\beta$-amyloid precursor protein (hAPP) promotes the deposition of human $\mathrm{A} \beta$ in cerebral vessels. ${ }^{12}$ In hAPP/TGF- $\beta$ l bigenic mice, in spite of its amyloidogenic effects on the cerebral vasculature, TGF- $\beta 1$ strongly reduces the overall cerebral $A \beta$ load by inhibiting the formation of neuritic plaques in the brain parenchyma. ${ }^{14}$

The levels of TGF- $\beta 1$ in the central nervous system are reportedly increased greatly in response to ischaemic, exciotoxic, and traumatic brain injury. ${ }^{17-21}$ Eight polymorphisms of the TGF- $\beta 1$ gene $(T G F-\beta 1)$ located to $19 \mathrm{q} 13.1-13.3^{22}$ have been detected. ${ }^{23} 24$ Although the details of TGF- $\beta 1$ expression are still unclear, polymorphisms of the TGF- $\beta 1$ may play a role in the control of the TGF- $\beta 1$ level in plasma. ${ }^{24-26}$
Recently, one of these polymorphisms, a T/C transition at nucleotide 29 in the region encoding the signal sequence, which results in a Leu/Pro substitution at amino acid 10, has been reported to be associated with the serum concentration or production of TGF- $\beta 1^{242527}$ and with diseases such as osteoporosis, ${ }^{25}$ myocardial infarction, ${ }^{24}$ rheumatoid arthritis, ${ }^{28}$ and invasive breast cancer. ${ }^{27}$

In the present study, we investigated whether the $\mathrm{T} / \mathrm{C}$ polymorphism at codon 10 in exon 1 of the TGF- $\beta 1$ is associated with CAA in elderly individuals.

\section{SUBJECT AND METHODS}

\section{Patients}

We studied 167 Japanese patients (age 62-104 years; mean \pm SD, $86.0 \pm 7.8$ years). They were consecutive autopsy cases in a large geriatric hospital, excluding cases in which brain samples could not be obtained for study and cases of neurodegenerative diseases other than AD. Consent was obtained from all families of participants at autopsy. This study project was approved by the ethics committee of each institution. The 167 patients included 73 patients with sporadic $\mathrm{AD}$, in which the neuropathological findings satisfied the criteria of the Consortium to Establish a Registry for Alzheimer's Disease, ${ }^{29}$ and 94 subjects without $\mathrm{AD}$ or other neurodegenerative disorders. All the $\mathrm{AD}$ patients clinically showed dementia on the basis of the criteria of American Psychiatric Association. ${ }^{30}$ There was no significant difference in the age at death between $\mathrm{AD}(86.1 \pm 8.0)$ and non-AD $(86.0 \pm 7.7)$ groups. No familial cases of AD or CAA were included in this series.

Abbreviations: $A \beta$, amyloid $\beta$ protein; $A D$, Alzheimer's disease; APOE, apolipoprotein E; CAA, cerebral amyloid angiopathy; hAPP, human $\beta$-amyloid precursor protein; $P C R$, polymerase chain reaction; TGF- $\beta 1$, transforming growth factor- $\beta 1$ 
Table 1 Distribution of the TGF- $\beta 1$ genotypes in Alzheimer's disease (AD) and non-AD

\begin{tabular}{llll}
\hline & AD $(\mathbf{n}=73)$ & Non-AD $(\mathbf{n}=94)$ & $\mathbf{p}$ \\
\hline Genotype, $n(\%)$ & & & \\
TT & $23(31.5 \%)$ & $24(25.5 \%)$ & \\
TC & $36(49.3 \%)$ & $41(43.6 \%)$ & NS \\
CC & $14(19.2 \%)$ & $29(30.9 \%)$ & \\
\hline
\end{tabular}

*Statistical difference in the TGF- $\beta 1$ genotypes between $A D$ and non-AD by $\chi^{2}$ test.

\section{Neuropathological evaluation of CAA}

Congophilic deposits with green birefringence under polarised light were identified as amyloid deposits. The cerebrovascular amyloid deposits were immunohistochemically confirmed to be $A \beta$. Using a large section of the occipital lobe (about $4 \times 4 \mathrm{~cm}$ in size), the numbers of meningeal and cortical vessels (small arteries and arterioles) with and without amyloid deposits were counted in the whole section, and the percentage of amyloid-laden vessels was calculated ( = CAA count). We examined the occipital lobe because it was the most frequently affected by CAA in our previous study in both $\mathrm{AD}$ and non-AD cases ${ }^{31}$ and seemed suitable for detecting CAA of very slight degree. The quantification was performed without knowledge of the TGF- $\beta 1$ or APOE genotypes. Severe vascular wall involvement was commonly found in patients with high CAA counts, and some of them presented with secondary degenerative changes - that is, CAA associated vasculopathies. However, we did not use data of such morphological changes because it was difficult to evaluate totally and quantitatively the extent of amyloid involvement of each blood vessel, and only a small number of patients with CAA associated vasculopathies were included in this series. We used only the CAA counts for our statistical analysis to represent the severity of CAA.

\section{Identification of the TGF- $\beta 1$ polymorphism}

Genomic DNA was isolated from the frozen brain tissue of all patients using a standard phenolchlorophorm extraction procedure. TGF- $\beta 1$ genotype was determined by a direct sequence method as previously described. ${ }^{23}$ Briefly, the first exon of the TGF- $\beta 1$ was amplified by polymerase chain reaction (PCR) with sense (5'-TCCTACCTTTTGCCGGGAGAC$\left.3^{\prime}\right)$ and antisense (5'-GTTGTGGGTTTCCACCATTAG-3') primers. The PCR products were sequenced with a fluorescencebased automated DNA sequencer (Prism 310; Applied Biosystems, CA, USA). The APOE genotype was also determined as previously described. ${ }^{5}$

\section{Statistical analysis}

Comparison of the distributions of the $\mathrm{AD}$ and non- $\mathrm{AD}$ patients over the TGF- $\beta 1$ genotype categories (TT, TC, and $\mathrm{CC})$ were performed using a $\chi^{2}$ test.

CAA counts were compared between the TGF- $\beta 1$ genotypes (TT, TC, and CC) in $\mathrm{AD}$, non- $\mathrm{AD}$, and all patients. Because the counts did not follow a normal distribution in any group, we used the Kruskal-Wallis test for the comparison as a nonparametric test. Similar analyses were performed according to the subgroups of $A P O E \in 4$ status. We also used the MannWhitney $\mathrm{U}$ test to compare CAA counts between $\mathrm{AD}$ and non$\mathrm{AD}$ patients. The correlation between the number of $\mathrm{T}$ allele and CAA counts was examined with Spearman's rank correlation analysis.

Statistical significance was defined as $p<0.05$. The statistical analyses were performed using StatView J-7.5 (Abacus Concepts, Berkeley, CA, USA).

\section{RESULTS}

Among the 167 patients examined, TT, TC, and CC genotypes of the TGF- $\beta 1$ polymorphism were found in 47,77 , and 43 individuals, respectively ( 0.51 in T-type allele frequency and 0.49 in C-type allele frequency). Age did not differ significantly between the genotypes. The distribution of the TGF- $\beta 1$ genotype in $\mathrm{AD}$ and non-AD is shown in Table 1 . The TGF- $\beta 1$ genotype was not significantly different between $\mathrm{AD}$ and non-AD subjects. There was a strong association between $\mathrm{AD}$ and the $A P O E$ E4 allele in this population $(\mathrm{p}<0.0001)$ as we previously reported in a smaller number of samples. ${ }^{32}$

Sixty two $(84.9 \%)$ of $73 \mathrm{AD}$ patients and $29(30.9 \%)$ of 94 non-AD patients were affected by CAA. Average values of CAA counts and numbers of patients with CAA in the TGF- $\beta 1$ genotypes are shown in Table 2. Average values of CAA counts were significantly different between TT, TC, and CC genotypes in all patients $(p=0.0026)$ and in the non-AD patients $(p=0.011)$, but not in the $A D$ patients. When the patients were categorised by APOE $€ 4$ status, the average CAA count was significantly different between the genotypes in the non- $\epsilon 4$ carriers $(p=0.0099)$ but not in the $\epsilon 4$ carriers (Table 2). In this population, the CAA count was significantly higher in the $\mathrm{AD}$ patients than in the non-AD patients $(\mathrm{p}<0.0001)$, and was higher in the $A P O E \in 4$ carriers than in the APOE non- $\epsilon 4$ carriers $(\mathrm{p}=0.002)$ (Table 2$)$.

The number of $\mathrm{T}$ alleles in the TGF- $\beta 1$ polymorphism showed a significant positive correlation with the CAA count in all patients $(\rho=0.255, \mathrm{p}=0.0011)$, non-AD patients $(\rho=0.316, \mathrm{p}=0.0033)$, and $A P O E$ non- $\epsilon 4$ carriers $(\rho=0.272, \mathrm{p}=0.0028)$, but not in the AD patients or $\epsilon 4$ carriers.

Table 2 Average cerebral amyloid angiopathy (CAA) counts in the TGF- $\beta 1$ genotype

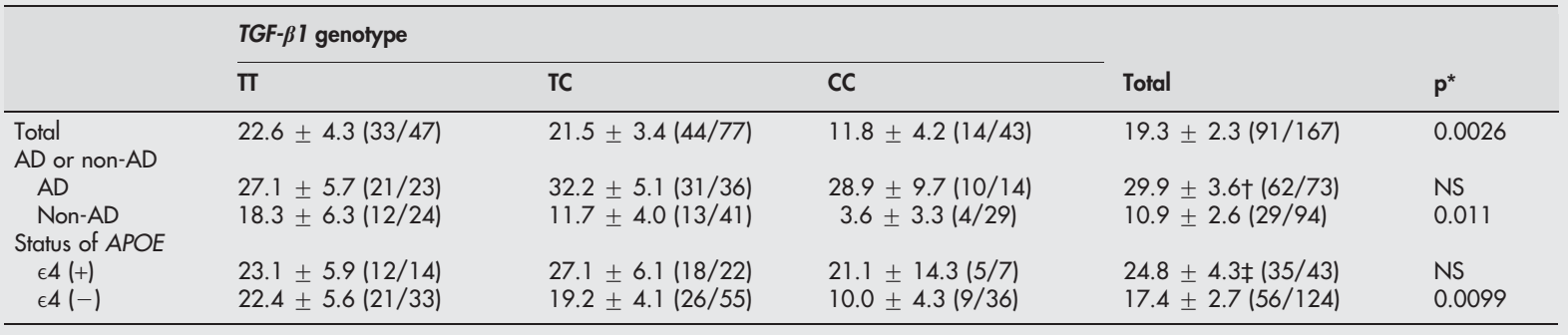

Values are means \pm SE. Values in parentheses are numbers of CAA patients/total patients. Average CAA counts are calculated by using the data from total patients.

${ }^{*}$ Statistical difference in CAA counts between the TGF- $\beta 1$ genotypes by Kruskal-Wallis test; $\uparrow p<0.0001$ (AD $v$ non-AD) by the Mann-Whitney U test; $\ddagger \mathrm{p}=0.002$ $(\in 4(+) \vee \in 4(-))$ by the Mann-Whitney U test. AD, Alzheimer's disease; APOE, apolipoprotein $E$; TGF- $\beta 1$, transforming growth factor- $\beta 1$. 


\section{DISCUSSION}

Our results revealed that the genotypes and number of $\mathrm{T}$ alleles of the $\mathrm{T} / \mathrm{C}$ polymorphism at codon 10 in exon 1 of the $T G F-\beta 1$ were associated with the severity of CAA. An increase in the number of $\mathrm{T}$ alleles in the TGF- $\beta 1$ polymorphism may be a risk factor of CAA in the elderly, especially for non-AD patients and $A P O E$ non- $€ 4$ carriers.

TGF- $\beta 1$ may be related to the pathogenesis of $\mathrm{AD}$ and CAA. ${ }^{11}{ }^{12}{ }^{14-16}$ It has been reported that cerebral TGF- $\beta 1$ levels are higher in $\mathrm{AD}$ patients than in non-demented controls, ${ }^{15}{ }^{16}$ and that TGF- $\beta 1$ is present in senile plaques and is overexpressed in AD. ${ }^{11}$ It has been shown in recent studies ${ }^{12}{ }^{14}$ that increased production of TGF- $\beta 1$ promotes deposition of $A \beta$ in cerebral blood vessels, but reduces plaque formation in the brain parenchyma in $\mathrm{AD}$ patients or $\mathrm{AD}$ mice models. By contrast, TGF- $\beta 1$ has been reported to potentiate $A \beta$ generation in astrocytes and transgenic mice promoting $A \beta$ deposition in the brain..$^{33}$ TGF- $\beta 1$ may have complex effects on the expression and processing of APP, A $\beta$ clearance from the brain, and cerebrovascular $\mathrm{A} \beta$ deposition, probably through activation of astrocytes and microglias. ${ }^{14}{ }^{33}$

Association of TGF- $\beta 1$ polymorphisms with $\mathrm{AD}$ has been studied, including the polymorphisms at $-800,-509$, codon 263 in exon 5 , and +25 in the TGF- $\beta 1 .{ }^{34}{ }^{35}$ A weak association of the $-509 \mathrm{~T}$ allele with $\mathrm{AD}$ was reported in an American population; ${ }^{34}$ however, there was no association between the -509 polymorphism and $\mathrm{AD}$ in another study. ${ }^{35}$ The other polymorphisms of TGF- $\beta 1$ were not associated with $\mathrm{AD} .^{34}{ }^{35} \mathrm{In}$ this study, we investigated the association of the T/C polymorphism at codon 10 in exon 1 of the TGF- $\beta 1$ with $\mathrm{AD}$ for the first time, and failed to find any significant association. Therefore, the association of the TGF- $\beta 1$ polymorphism with CAA would be independent of $\mathrm{AD}$, although there is a close relation between CAA and $\mathrm{AD} .^{36}$

The T/C polymorphism of the TGF- $\beta 1$ results in the Leu/Pro substitution of TGF- $\beta 1$, which is located in the 29 -residue signal peptide sequence. ${ }^{24}{ }^{25}$ The TGF- $\beta 1$ polymorphism may affect the function of the signal peptide, perhaps influencing intracellular trafficking or export efficiency of the preproprotein, and the TGF- $\beta 1$ genotypes may be associated with the production of this protein. The $\mathrm{T}$ allele of the TGF- $\beta 1$ polymorphism has been reported to be associated with reduced levels of TGF- $\beta 1$ proteins in serum. ${ }^{24}{ }^{25}$ In transfection experiments with HeLa cells, the signal peptide with Pro at residue 10 encoded by the $C$ allele causes an increase in secretion of TGF- $\beta 1$ compared with the Leu form encoded by the $\mathrm{T}$ allele. ${ }^{27}$

If the $\mathrm{T}$ allele is associated with reduced levels of TGF- $\beta 1$ in the brain as well as in serum, ${ }^{24}{ }^{25}$ our data suggest that reduced TGF- $\beta 1$ levels may be associated with increased severity of CAA. This is inconsistent with the reports that TGF- $\beta 1$ would promote CAA in $\mathrm{AD}$ patients and $\mathrm{AD}$ mice models. ${ }^{12}{ }^{14}$ This discrepancy may be related to the difference in the role of TGF- $\beta 1$ for cerebrovascular amyloid deposition between $\mathrm{AD}$ and non- $\mathrm{AD}$ patients, or the difference in the role of this polymorphism in expression of TGF- $\beta 1$ between systemic circulation and brain. We do not have any definite explanation for this discrepancy because we have no data on the TGF- $\beta 1$ concentration in the central nervous system from these patients. Our results indicate an important role of TGF- $\beta 1$ in CAA, requiring further study to elucidate the pathomechanism.

CAA-related cerebrovascular disorders include lobar cerebral and cerebellar haemorrhages, leucoencephalopathy, and cortical small haemorrhage. ${ }^{2}$ Patients with asymptomatic CAA may develop cerebral haemorrhages following antithrombotic or anticoagulation treatment against thromboembolic disorders ${ }^{37}$ or $\mathrm{A} \beta$ immunotherapy against $\mathrm{AD}{ }^{39}$ Because there are no definitive biological markers or imaging technologies for definite diagnosis of the CAA, except for pathological examination of the brain, further development of tests to evaluate risk of CAA is necessary. AD and APOE $€ 4$ have been reported to be independent risk factors of CAA, but CAA is also observed in non-AD or APOE non- $€ 4$ carriers. ${ }^{1-10} 31{ }^{35}$ Interestingly, the polymorphism of TGF- $\beta 1$ is a risk factor of CAA especially in non-AD or APOE non- $\epsilon 4$ carriers, which may contribute to prediction of CAA in such cases.

The current study has limitations; our sample population was relatively small and obtained from an autopsy series in a geriatric hospital. Our results warrant further study with a larger sample size from populations with various ethnic backgrounds.

In conclusion, our results suggest that the T/C polymorphism at codon 10 in exon 1 of the TGF- $\beta 1$ would be associated with the severity of CAA, especially in non-AD or APOE non$\epsilon 4$ carriers.

\section{ACKNOWLEDGEMENTS}

We thank Dr J Adachi (The Institute of Statistical Mathematics) for his useful comments on our statistical analysis. The study was supported by grants from the Amyloidosis Research Committee (to MY) and the Research Committee of Genetic Analyses of Cerebrovascular Disorders (to MY), the Ministry of Health, Labour and Welfare, Japan, and by a Grant-in-Aid for Scientific Research (to MY) from the Ministry of Education, Culture, Sports, Science and Technology, Japan.

\section{Authors' affiliations}

T Hamaguchi, S Okino, M Yamada, Department of Neurology and Neurobiology of Aging, Kanazawa University Graduate School of Medical Science, Kanazawa, Japan

N Sodeyama, H Mizusawa, Department of Neurology and Neurological Science, Tokyo Medical and Dental University, Tokyo, Japan

Y Itoh, E Otomo, Department of Internal Medicine, Yokufukai Geriatric Hospital, Tokyo, Japan

A Takahashi, Organ and Function Pathology Division, Yokufukai Geriatric Hospital, Tokyo, Japan

M Matsushita, Department of Neuropathology, Tokyo Institute of Psychiatry, Tokyo, Japan

Competing interests: none declared

\section{REFERENCES}

1 Vinters HV. Cerebral amyloid angiopathy: a critical review. Stroke 1987; 18:311-24.

2 Yamada M. Cerebral amyloid angiopathy: an overview. Neuropathology 2000;20:8-22.

3 Greenberg SG, Rebeck GW, Vonsattel JPG, et al. Apolipoprotein E $\epsilon 4$ and cerebral hemorrhage associated with amyloid angiopathy. Ann Neurol 1995;38:254-9.

4 Premkumar DRD, Cohen DL, Hedera P, et al. Apolipoprotein E $\epsilon 4$ alleles in cerebral amyloid angiopathy and cerebrovascular pathology associated with Alzheimer's disease. Am J Pathol 1996;148:2083-95.

5 Itoh Y, Yamada M, Suematsu N, et al. Influence of apolipoprotein E genotype on cerebral amyloid angiopathy in the elderly. Stroke 1996;27:216-18.

6 Yamada M, Itoh Y, Suematsu N, et al. Lack of an association between apolipoprotein $E \in 4$ and cerebral amyloid angiopathy in elderly Japanese. Ann Neurol 1996;39:683.

7 Nicoll JAR, Burnett C, Love S, et al. High frequency of apolipoprotein E $\epsilon 2$ in hemorrhage due to cerebral amyloid angiopathy. Ann Neurol 1997;41:716-21

8 Yamada M, Sodeyama N, Itoh Y, et al. Association of presenilin-1 polymorphism with cerebral amyloid angiopathy in the elderly. Stroke 1997;28:2219-21.

9 Yamada $M$, Sodeyama N, ltoh $Y$, et al. Association of $\alpha 1$-antichymotripsin polymorphism with cerebral amyloid angiopathy. Ann Neurol 1998;44:129-31.

10 Yamada M, Sodeyama N, Itoh Y, et al. Association of neprilysin polymorphism with cerebral amyloid angiopathy. J Neurol Neurosurg Psychiatry 2003;74:749-51

11 Finch CE, Laping NJ, Morgan TE, et al. TGF- $\beta 1$ is an organizer of responses to neurodegeneration. J Cell Biochem 1993;53:314-22.

12 Wyss-Coray T, Masliah E, Mallory M, et al. Amyloid genic role of cytokine TGF- $\beta 1$ in transgenic mice and Alzheimer's disease. Nature 1997;389:603-6. 
13 Frautschy SA, Yang F, Calderön L, et al. Rodent models of Alzheimer's disease: rat $A \beta$ infusion approaches to amyloid deposits. Neurobiol Aging 1996;17:311-21.

14 Wyss-Coray T, Lin C, Yan F, et al. TGF- $\beta 1$ promotes microglial amyloid- $\beta$ clearance and reduces plaque burden in transgenic mice. Nat Med 2001;7:612-18.

15 Flanders KC, Ren RF, Lippa CF. Transforming growth factor- $\beta$ s in neurodegenerative disease. Prog Neurobiol 1998:54:71-85.

16 Akiyama H, Barger S, Bradt B, et al. Inflammation and Alzheimer's disease. Neuroinflammation Working Group. Neurobiol Aging 2000;21:383-421.

17 Da Cunha A, Jefferson JA, Jackson RW, et al. Glial cell-specific mechanisms of TGF- $\beta 1$ induction by IL- 1 in cerebral cortex. J Neuroimmunol 1993:42:71-86.

18 Lehrmann E, Kiefer R, Finsen B, et al. Cytokines in cerebral ischemia: expression of transforming growth factor $\beta-1$ (TGF- $\beta 1$ ) mRNA in the postischemic adult rat hippocampus. Exp Neurol 1995;131:114-23.

19 Lindholm D, Castren E, Kiefer R, et al. Transforming growth factor- $\beta 1$ in the rat brain: increase after injury and inhibition of astrocyte proliferation. J Cell Biol 1992; 117:395-400.

20 Nichols NR, Laping NJ, Day JR, et al. Increase in transforming growth factor- $\beta$ mRNA in hippocampus during response to entorhinal cortex lesions in intact and adrenalectomized rats. J Neurosci Res 1991;28:134-9.

21 Wang X, Yue TL, White RF, et al. Transforming growth factor- $\beta 1$ exhibits delayed gene expression following focal cerebral ischemia. Brain Res Bull 1995;36:607-9.

22 Fujii D, Brissenden JE, Derynck R, et al. Transforming growth factor beta gene maps to human chromosome 19 long arm and to mouse chromosome 7. Somat Cell Mol Genet 1986;12:281-8.

23 Cambien F, Richard S, Troesch A, et al. Polymorphisms of the transforming growth factor- $\beta 1$ gene in relation to myocardial infarction and blood pressure. The Etude Cas-Témoin de l'Infarctus du Myocarde (ECTIM) Study. Hypertension 1996;28:881-7.

24 Yokota $M$, Ichihara S, Lin TL, et al. Association of a T29 $\rightarrow$ C polymorphism of the transforming growth factor- $\beta 1$ gene with genetic susceptibility to myocardial infarction in Japanese. Circulation 2000;101:2783-7.

25 Yamada Y, Miyauchi A, Goto J, et al. Association of a polymorphism of the transforming growth factor- $\beta 1$ gene with genetic susceptibility to osteoporosis in postmenopausal Japanese woman. J Bone Miner Res 1998;13:1569-76.
26 Grainger DJ, Heathcote K, Chiano M, et al. Genetic control of the circulating concentration of transforming growth factor type $\beta 1$. Hum Mol Genet 1999;8:93-9

27 Dunning AM, Ellis PD, McBride S, et al. A transforming growth factor $\beta 1$ signal peptide variant increases secretion in vitro and is associated with increased incidence of invasive breast cancer. Cancer Res 2003;63:2610-15.

28 Sugiura $Y$, Niimi T, Sato $S$, et al. Transforming growth factor $\beta 1$ gene polymorphism in rheumatoid arthritis. Ann Rheum Dis 2002;61:826-8.

29 Mirra S, Heyman A, McKeel D, et al. The Consortium to Establish a Registry for Alzheimer's Disease (CERAD). Part II: standardization of the neuropathologic assessment of Alzheimer's disease. Neurology 1991;41:479-86.

30 American Psychiatiric Association. Diagnostic and Statistical Manual of Mental Disorders, 3rd ed. Washington, DC: American Psychiatric Association, 1987.

31 Yamada M, Tsukagoshi $\mathrm{H}$, Otomo $\mathrm{E}$, et al. Cerebral amyloid angiopathy in the aged. J Neurol 1987;234:371-6.

32 Sodeyama N, Yamada M, Itoh Y, et al. No association of paraoxonase gene polymorphism with atherosclerosis or Alzheimer's disease. Neurology 1999;53:1146-8

33 Lesné S, Docagne F, Gabriel C, et al. Transforming growth factor- $\beta 1$ potentiates amyloid- $\beta$ generation in astrocytes and in transgenic mice. J Biol Chem 2003;278:18408-18.

34 Luedecking EK, DeKosky ST, Mehdi $\mathrm{H}$, et al. Analysis of genetic polymorphisms in the transforming growth factor- $\beta 1$ gene and the risk of Alzheimer's disease. Hum Genet 2000;106:565-9

35 Araria-Goumidi L, Lambert J C, Mann D M A, et al. Association study of three polymorphisms of TGF- $\beta 1$ gene with Alzheimer's disease. J Neurol Neurosurg Psychiatry 2002;73:62-4.

36 Yamada M. Risk factors for cerebral amyloid angiopathy in the elderly. Ann NY Acad Sci 2002;977:37-44

37 Rosand J, Hylek EM, O'Donnell HC, et al. Warfarin-associated hemorrhage and cerebral amyloid angiopathy. A genetic and pathologic study. Neurology 2000:55:947-51.

38 Winkler DT, Biedermann L, Tolnay M, et al. Thrombolysis induces cerebral hemorrhage in a mouse model of cerebral amyloid angiopathy. Ann Neurol 2002;51:790-3.

39 Pfeifer M, Boncristiano S, Bondolfi L, et al. Cerebral hemorrhage after passive anti-A $\beta$ immunotherapy. Science 2002;298:1379. 